Encountering automation: redefining bodies through stories of technological change

David Bissell

School of Geography

The University of Melbourne

221 Bouverie St

Carlton, Victoria 3053,

Australia

david.bissell@unimelb.edu.au

+61383443889

Accepted for publication in Environment and Planning D: Society and Space

September 2020 


\title{
Encountering automation: redefining bodies through stories of technological change
}

\begin{abstract}
This article enhances our understanding of the thoroughly embodied nature of knowledge production in relation to automation by demonstrating how making sense of automation is a generative process, rather than the demystification of an already existing object of analysis. It argues that the process of knowing automation involves situated encounters that transform bodies at the level of their indeterminate capacities to affect and be affected which, in turn, contributes to the production of what automation is. Contrasting with more generalised diagnoses about how automation is deskilling or reskilling bodies, it evaluates the constitutive role of situated encounters that register in sensing bodies for reshaping capacities. Focusing on iron ore mining in Australia, an industry sector that is currently increasing its automated operations, the paper draws on a series of fieldwork encounters with people differently positioned in the mining sector. Through the presentation of five stories that incorporate combinations of these fieldwork encounters, the paper constructs a more complex picture of how automation is redefining different bodies. Rather than taken to be mere representations of automation, it argues that the listening to and telling of stories about automation is a form of encounter that redefines bodies in the process.
\end{abstract}

\section{Keywords}

affect, stories, embodiment, emotion, technology, labour

\section{Introduction}

There exists deep concern that the intensified automation of jobs presently undertaken by humans will lead to mass unemployment with profound social, cultural and economic implications (Ford, 2015; Brynjolfsson and McAfee, 2014). This universalised premonition has necessarily catalysed social scientific research on diverse forms of technological automation (Elliott, 2019; Pink and Sumartojo, 2018). Yet geographers have long appreciated the spatial complexities of automation, with earlier work revealing how technological automation changes labour requirements in industryspecific ways in different places (Massey, 1984; Wallace, 1985). In contrast to universalised claims, geographers have explained how automation changes labour in terms of agency, responsibility and decision-making across a variety of different domains and through diverse sites (Boyer and England, 2008). Echoing Massey's (1984) contention that automation technologies create power geometries 
where some are in control of production while others are on the receiving end, more recent work has deepened our understanding of how specifically digital automation is differently affecting labour. Where research by Birtchnell and Elliott (2018) explains how music industry professionals use automation to enhance their creativity, Kanngieser's (2013) work on warehouse pickers explores how automation subjects other bodies to oppressive forms of management. Moreover, as Richardson (2018) explains, automation technologies are changing the sort of bodies that are required to labour, since the digital automation of tasks previously undertaken by humans 'deskills' some while new jobs associated with automation's requirement for digital labour 'reskills' others. In response to concerns about intensified automation on labour, geographers have thus revealed how socio-spatial formations are changing in different ways. This ontological focus has illuminated how bodies are evolving with these technologies (Rose, 2017; Kinsley, 2019), echoing Thrift's proposition that automation is leading to the 'redefinition' of bodies (Thrift, 2011, 10). However, an ontological concern for diagnosing what, exactly, is happening, needs pairing with a heightened epistemological sensitivity to how automation becomes known and understood by different bodies, 'redefining' them in the process. As feminist digital geographers have highlighted, this neglected epistemological aspect is practically challenging and politically complex. In stressing the difficulty of 'empirically grappling with the complexities of the significance and implications of digital technologies in the daily lives of actual people' $(2018,639)$, Elwood and Leszczynski invite renewed attention to the convoluted situatedness of technological knowledge production. The issue of epistemology is vital because it directly informs what we take automation to be. Accordingly, this article aims to enhance understanding of the thoroughly embodied nature of knowledge production in relation to automation by demonstrating how making sense of automation is a generative process in and of itself, rather than the demystification of an already existing object of analysis. My argument is that the process of knowing automation involves situated encounters that transform bodies at the level of their indeterminate capacities to affect and be affected which, in turn, contributes to the production of what automation is.

Foregrounding how automation is produced through situated encounters, this article develops cultural geographical thought on the affective dimensions of encounter (Wilson, 2017). This concept helps to appreciate the multiple reconfigurations of power that happen when bodies encounter other bodies, rather than situations being overdetermined by an extrinsic source of power. If every encounter involves a reconfiguration, big or small, of bodily capacities to affect and be affected, then to encounter is to foster change (Anderson and Harrison, 2010). Encounter provides a powerful redress to both technocentric accounts of automation that present a universalised view from nowhere (Ford, 2015) and political economy analyses that take empirical occasions involving 
automation to be the mere playing out of pregiven power relations (Woolley, 2018). This is not to discount political economy preoccupations such as the power of different institutions. Rather, it is about appreciating that there is also a productive significance of situated bodily engagements with different forms of automation to create new knowledges. In short, encounter helps to consider how automation affects specific bodies in spatially contingent ways in contrast to generalised diagnoses of deskilling or reskilling; it helps to appreciate the constitutive role of bodily affectivity in shaping what automation is; and it assists in developing more multiple and transitional understandings of automation, rather than something that is fixed or known.

The substantive focus of this article is the iron ore mining sector in Australia, for four reasons. First, as Richardson (2018) suggests, automation must be evaluated in terms of 'actually existing' manifestations in different industries, rather than more generalised diagnoses that are insensitive to contextual specificity. Second, there is an absence of geographical research on automation in this sector, with existing analyses focusing on the service sector (Richardson, 2019), mobility (Hopkins and Schwanen, 2018), housing (Fields, 2019) and urban infrastructure (Pink and Sumartojo, 2018). Third, the mining sector is economically significance to Australia, credited with preventing recession (Sheppard, 2013), as well as being a political drawcard through the promise of new jobs for regional areas. Fourth, the mining sector has increased the intensity of digital automated operations over the past decade as autonomous mining drills, trains and trucks that are managed from remote control centres have been developed to enhance economic productivity at a time of volatile iron ore prices.

Automation is a spatially complicated object of analysis, making the question of researching encounters with automation challenging. As Thrift and French (2002) explain, new forms of digitally mediated automation often manifest as a 'background' hum that is not necessarily consciously registered by the bodies that it affects. Some geographical engagements with automation have resolved this challenge by studying discrete machines such as automated robots whose spatial perturbations can be observed (Del Casino, 2015). However, Savat and Chau warn that 'the actual materiality of the machine is not where we can locate the machine as such, nor can we locate it in its individual components' $(2017,61)$. Instead, they encourage us to 'consider the organisation of those components, including what drives that very organisation or arranging and assembling of the components' (2017, 61, emphasis added). Taking this more expansive understanding of the materiality of automation, my approach was to initiate encounters with people whose bodies have been differently affected by automation in the resource sector. Since automation has become such a pressing object of concern for this sector, automation is less a background hum and more a foreground roar that has prompted sustained reflection by differently situated bodies. The article is based on semi-structured interviews with fifteen people differently positioned in the iron ore mining 
sector in Australia, from directors to operatives, and from educators to equipment manufacturers. The criteria for recruitment was an involvement in mining automation and a willingness to talk about it. Initial interviews were with prior industry contacts and subsequent interviews involved a combination of snowballing from these participants and direct invitations. With the exception of one phone interview, all interviews were in-person. One interview involved a tour of a mining facility. Consistent with the aim of this article, this number of participants was sufficient for probing the diversity of ways that people in the sector spoke about automation.

In advocating for a feminist digital geography, Elwood and Leszczynski (2018) highlight the potentials of non-hegemonic epistemologies and feminist methodologies for disrupting dominant ways of knowing digital technologies. They invite geographers to engage with queer and critical race theory, postcolonial feminism, and black and queer code studies to challenge disciplinary exclusions and provide new insights into digital mediations of complex bodies. Complimenting this focus on nonhegemonic epistemologies, this article develops storytelling as a methodological technique that is adept at drawing out the multiple ways that automation becomes produced by differently situated bodies. This technique has roots in feminist geographies that demonstrate how storytelling can attend to minor knowledges produced through struggles in specific sites that might be excluded by hegemonic discourses (Nagar, 2013). Although the role of talk for understanding working relations with technology has a long history (Orr, 1996), interest in storytelling has recently been renewed in geography as a response to critiques of representationalism (Lorimer and Parr, 2014). Echoing earlier work that explains how technological mediations become known through collective sensemaking (Suchman, 1995), stories are becoming understood as the process through which bodies make sense of their experiences, where experiences become thought. As Rose (2016) argues, rather than taking empirical material as evidence that might confirm or deny something already thought, in other words the end-point of thinking, stories can be acknowledged as the origins of thinking and feeling. Stories are therefore a response to a situation, rather than a mirrored reflection of a situation. As Stewart contends, in contrast to 'deadening realism of finished forms and social facts' $(2016,35)$, storied description is a 'minor composition' that responds to the 'shaken profusion of things throwing together, flourishing, or collapsing' $(2016,33)$.

Taking Thrift's notion of bodily redefinition as a cue, my argument is that storytelling plays a key but overlooked role in the evolution of automation. This is because in addition to its representational dimension, storytelling also catalyses thinking and feeling through its performative dimension. So, rather than imagining automation as something singular and stable that can be relayed through a sufficiently authoritative account, different stories enact different understandings of automation. Acknowledging this performative dimension means that bodies are being redefined in part through 
the stories that are heard and told about automation in two ways. First, through different storied expressions of automation, different bodies become differently defined as they are expressed as more or less capacitated. Each interview encounter involved someone telling me a story about automation changes that they have experienced. Storytelling was a creative technique for my participants and the interview was a space that enabled them to reflect on and make sense of the changes they were experiencing. Second, storytelling is an encounter that changes bodily capacities for the storyteller and listener in subtle but significant ways. Rather than seeing my role as an omniscient arbiter, I began to appreciate that my body was being redefined through encountering these automation stories, profoundly shifting my felt dispositions about technological automation in the process.

Appreciating the formative role of vernacular epistemologies through storytelling means that rather than imagining automation as something that is happening 'out there', automation is being encountered and therefore transformed in a much more dispersed range of sites. Where technocentric discourses on automation attempt to reveal the 'finished forms and social facts' that Stewart laments, as this article unfolds, it acknowledges how automation itself might be something more transitional, indeterminate and multiple. The political value of acknowledging this instability is to counter deterministic narratives of automation which imply that the site and path of action has already been decided. Heeding Rose's remarks on the interruptive capacities of stories to 'affect, move, or incite' $(2016,135)$, storying automation might also help to interrupt our intellectual automations-our scholarly habits of thinking about automation. Rather than reproducing well-worn accounts about what automation is supposedly doing, presenting automation through its incommensurable qualities, whose richness and complexity cannot be collapsed into universalised narratives, potentially writes against the grain, charging us to rethink how automation might be redefining bodies.

This article comprises five fieldwork stories about mining automation that took place at different sites with different people. Some stories are based on a single interview while others incorporate multiple voices where what was said resonated with the stories of others. Cognisant of Brigstocke and Noorani's suggestion that new kinds of political agency might emerge 'when voices have to be assembled rather than merely amplified' $(2016,1)$, telling diverse stories side by side enhances a sense of the multiplicity of automation. Each story is followed by an analytical reflection on the significance of bodily affectivity for understanding automation, cued by how the story affected me. These analytical reflections aim to intensify the force of the stories, such that their congruences and disjunctures might be felt with greater acuity. 


\section{Story 1: Encountering storm fronts}

"Australians need to 'wake up' to the robot threat." "Australia must prepare for massive job losses due to automation." Over some years I had become used to such headlines. Through their urgent tones they issued a warning of a mass collective slumber that risks catching us off guard. There was a looming quality to these declarations whose performative powers seemed to be about preparing us to collectively brace for impact. Accompanying diagrams often indicated the jobs which were most at risk from automation. Mining was always in the high-risk zone. Yet in spite of their universal address, who these articles were written for seemed more of a mystery. Some headlines followed with advice for diligent readers, recommending they should undertake a "skills inventory" to identify the other jobs they could do and what skills they would need to attain them. Judging by the snarky online comments below these stories, such well-intentioned advice didn't go unpunished.

Some of what was being implied by these headlines materialised for me while leafing through the pages of a regional airline seatback magazine, high in the sky, profiling mining futures in the Pilbara region of Australia. Huge yellow trucks were on the move, lights blazing, dust billowing, yet without drivers in the seat. Autonomous Haulage System trucks were the future of the mine, so the article said. There was something confronting about seeing huge autonomous trucks growl across the pages of a publication of an airline whose lifeblood was transporting mine workers from their urban homes to remote mine sites, many of whom would likely be truck drivers. Was this a benevolent warning to the remaining truck drivers who might be sitting in this seat at a later date, that they should undertake a "skills inventory," I wondered? A little later in the journey, feeling unnerved, from my window seat, I could just make out an open cut mine below and I wondered whether these trucks were already there. Collectively, these articles seemed to revel in both the delight and horror of workplaces being "taken over" by robots, giving automation the appearance of an unstoppable storm front rolling in from a distant elsewhere. Automation was at a distance, even from the window of the flight I was taking. Yet at this distance, automation was curiously devoid of people.

\section{Felt ecologies}

Commentators pronouncing the 'second machine age' have made grave forecasts about the disruptive impact of technological change on human workers. Brynjolfsson and McAfee write that 'technological progress is going to leave behind some people, perhaps even a lot of people, as it races ahead' $(2014,11)$. They write that 'there's never been a worse time to be a worker with 'ordinary' skills and abilities to offer, because computers, robotics and other digital technologies are acquiring these skills and abilities at an extraordinary rate' $(2014,11)$. Their predictions about jobless growth are emphasised in Frey and Osborne's (2013) evaluation of the impact of digitisation 
on 702 occupations which surmises that 47 percent of total US employment involving routine intensive occupations are at risk. Ford's forecasting of a 'jobless future' is bleaker, writing that 'artificial intelligence is already well on its way to making even good jobs obsolete. As progress continues, blue- and white-collar jobs alike will evaporate, causing massive unemployment and the implosion of the consumer economy itself' $(2015, \mathrm{xx})$. As this story indicates, these evaluations have cascaded into the public realm through popular publications.

These declarations have spurred critique from social scientists concerned about pervasive technological determinism. As Forlano and Halpern point out, 'these powerful and far reaching narratives focus on the replacement of workers with technologies in a linear and technologically deterministic manner rather than acknowledging the complex, non-linear, and iterative relationship between activism, social change and technology' $(2015,33)$. Three critiques puncture these futurist narratives. First, political critiques trace the obscured power relations at play in the evolution of automation technologies. Wajcman (2017), for instance, laments how 'political questions are too often lost in our obsession with the robotic revolution we are set to witness' $(2017,3)$. The real problem, Wajcman suggests, is the 'rise of an even more powerful elite of male, white, Silicon Valley engineers whose values and biases will inevitably shape the technical systems they design' $(2017,4)$. Political critiques emphasise that new jobs have been created. Indeed, new technologies require forms of labour that are obscured in these debates such as data processing that requires human operation (Irani, 2015). Second, historical critiques show that these diagnoses have been made before. As Wise remarks, 'the worry that we will become enslaved to our machines... is far from new' $(1998,418)$. Recall Keynes's prediction of mass technological unemployment 'due to our discovery of means of economising the use of labour outrunning the pace at which we can find new uses for labour' $(1933,3)$. Other historical critiques illuminate the continuities of automation, connecting mechanical 'automata' of the early modern period with the contemporary robot (Stephens and Heffernan, 2016). Third, ecological critiques describe a more complex imbrication of the social and the technical. Drawing on post-humanist thought, in contrast to a universal humanistic body that technology threatens, these critiques stress the ever-changing nature of bodies in relation to technology. Latour's (1993) work emphasises how any social process relies on a complex ecology of human actors and non-human actants. Stiegler (2010) takes a related but different approach by stressing the co-emergence of the human with the technical to show that humans have always been 'prosthetic', developing tools that respond to an essential lack.

Returning to the story, the disembodied media articles can imply a view from nowhere, that the path of automation is inevitable, and that navigating this troubling situation is the individualised responsibility of workers. Intellectually, their veracity can be deflated by these three critiques. 
However, there is a crucial bodily dimension that these critiques overlook. This story demonstrates that media accounts are encountered somewhere, highlighting the neglected role of geographically situated bodily registrations. At work, while engaging with critiques of automation, to me such media accounts often seemed frustratingly sensationalist. Yet when cocooned in an airline cabin, the affectivity of these accounts became highly intense. Sitting there, knowing that miners take this flight, reading a dazzlingly illustrated account of the rise of automated haulage trucks, and then sighting a tiny mine site below together worked to intensify my bodily registration of empathy for those miners who I imagined might be panicked or enraged by seeing this article. On that flight, for the first time, I was struck by a sense of foreboding about what automation developments might be doing.

In short, while there is a growing body of important work that critiques technologically determinist accounts of automation politically, historically and ecologically, these critiques do not adequately consider the bodily registration of accounts of automation, technologically determinist or otherwise. In this regard, it is surprising that despite a rich seam of feminist work that acknowledges the centrality of feeling in the production of new social formations relating to employment, wellbeing and intimate relations (Bondi, 2014), many analyses of automation overlook the productive role of bodily affectivity. This first story indicates that how we come to be affected-or not-by the stories that we hear about automation is a crucial but overlooked part of the debate. As the story demonstrates, accounts of automation can be forceful (Anderson, 2019), but the way that they affect bodies is geographically circumstantial, mediated in part by the places that they are encountered in. If we take the force of representations seriously, they become a key part of how automation is produced and reproduced, multiplying the sites and agents of automation in the process.

\section{Story 2: Encountering shaming glare}

Shame burns. I'd arranged to speak with someone high-up in a mining company and I had emailed some indicative questions about how automation is impacting on the sector. After a spatter of cryptic one-line emails and being left to wait in a lobby for an age, I was being walked into a boardroom by a sharply dressed man. His complexion and manner suggested someone whose sensibilities had been chastened by working long hours in blistering mine sites. "I'm extremely busy today," he says, forcing my sense of deference further. He says they've been in meetings with an automation company all morning. "That sounds interesting," I offer, stumbling to fill the gap, but my response seems to only extend the felt space between us. 
There was another man in the boardroom. He'd requested back-up, either out of generosity or suspicion. After unfurling a preamble about the project, there is a pause. "We can't talk about company information," one of them says, glaring. Sitting at the head of the table, sandwiched between these two large men, my fragile attempt at composure evaporates. My face is burning and I wish this chair would swallow me. "Only last week we had some Japanese company asking us for information." I understand, of course. Intellectual property is key to their profitability and I am an outsider. The questions I was going to ask melt from memory and I fumble some safer questions, clumsily expressed and numbingly generic. They look at me blankly. "We can't talk specifically about what we do," says one, as if they are out-behaving each other. They talk in hypotheticals about automation in other industries. As one speaks, the other looks at his phone, his watch, his phone again. Thinking about things I'd read, I ask about how automation deals with indeterminacy. One of them raises his eyebrows and says confidently that the world is actually very much determinate and determinable. I feel the vertigo of the chasm between our realities once more.

I catch sight of one of their watches and see that half an hour has passed. I thank them for their time. As we leave, he says "Just watch if you're talking to other people here that you understand the limits of what we can do for you." Spat out through the corridors, and feeling utterly depleted, I brush past framed prints of gaping landscape sores and gigantic ships being loaded with orange ore. His aggressive words of send-off seem to speak to this landscape. "The limits of what we can do." I'm hit by the destruction this company has inflicted on Country through its aggressive pursuit of collective resources whose profits have been privatised, and where automation is the new weapon.

\section{Affective transitions}

In the aftermath of what felt like a failed corporate interview, I felt I'd learned nothing about automation. But just what was being concealed from me is made more complex in light of Hayles's (2014) argument that 'black-boxing' is part of the operative logic of automation. Her point is that it is largely the 'non-conscious cognitive processes' of machines that make up contemporary digital automation where device-to-device communication bypasses humans altogether. Hayles moves beyond an anthropocentric focus on the liberal humanist subject to explain how cognition is 'embodied throughout human flesh and extended into the social and technological environment' (Hayles, 2006, 161). Admitting that 'human awareness comprises [only] the tip of a huge pyramid of data flows' (Hayles, 2006, 161) is politically significant because many processes are designed to evade critical scrutiny (Amoore and Raley, 2017). Perhaps in spite of their management roles, the men had nothing to share after all. 
Yet on reflection, I was learning something different about automation. For a start, I was learning that humans remain a critical part of automation ecologies that exceed data flows. Where Irani (2015) highlights the role of human data workers in apparently autonomous processes, this story flags the role of critical gatekeepers in mediating knowledge flows about digital automation and it intimates the value of these knowledges and the necessity for concealment in a competitive marketplace. Yet focusing on concealment alone overlooks how this encounter was also producing automation in a distinctive way. The concept of encounter is valuable because it emphasises not just the coming together of difference, but the creation of difference itself. Encounters are micropolitical transitions in bodily capacities to be affected and to affect, which may be felt in in bodily sensation as a kaleidoscope of different emotions (Massumi, 2015). Being reduced by dominating white, middle-aged, able-bodied men who were flexing their steely belief in a determinable world made me wonder whether the storm front declarations in the first story could be true. I resented the shame they inflicted on me and I wanted even more to believe in the critiques levelled at technocentric accounts of automation.

While not discounting the significance of concealed non-conscious machine processes, this story demonstrates that focussing on interfaces between informatic and physical domains 'elides some of the more subtle and nuanced modes of encounter and relationality' (Shepard, 2013, 483) that produce automation. Although the technical dimensions of mining automation were being withheld from me, this was an intensely felt encounter with an institutional dimension of automation that changed my sense of what automation is. Defining feeling as 'the ongoing constitution of life as lived' $(2018,21)$ and reflecting on the evolution of digital automation, Murphie argues that the question of what can be felt is a vitally important issue, where 'feeling itself-what is, what it does, and what the future of feeling might be-has become both a field of struggle and a complex openended question' $(2018,18)$. Where previously cocooned in an airline cabin I had felt mining automation through a general sense of unease, this diminution of powers by aggressive masculine posturing in the boardroom changed my perceptive capacities, catalysing a heightened sense of automation's destructiveness. This banal yet forceful encounter made palpable automation's operative role in facilitating capitalist accumulation, perpetuating colonial violence and Indigenous dispossession.

\section{Story 3: Encountering awestruck visions}

Martin was a global leader in mine automation whose every word radiated belief in his technology. "Automation is a different evolutionary path," he says. It's about creating "efficiencies on 
efficiencies, so things you thought were impossible are just a line of code." He says automation improves productivity through "military grade precision," and he recommends I read Kurtzweil and Friedman. Martin speaks without hesitation and I imagine these phrases being unfurled in beguilingly proselytic tones to boards of directors. His words echoed an equipment manufacturer, Harry, with whom I spoke previously, who described how automation reduces the "tremendous variation and waste in the system." Yet with Martin, I also sensed a deferential reverence for systems only on the cusp of being "tameable". He says at first "the trucks ran slower but longer, and then as the coders and the system controllers and the autonomy managers got more control over this thing, they would just tell the system to run a bit faster." Intrigued by such phrasing, I suggest the system had a life of its own. "Well it did do, absolutely did do," Martin says, in past tense, as if his own admission had surprised himself.

I'm struggling to reconcile Martin's effervescence with the robotic threat headlines. I ask, nervously, about human workers. Martin isn't fazed, acknowledging the "delicate balance between the human and the machine," But he says, "human operators had to not feel threatened by them." In the beginning, he notes that that in contrast to near-retirement and younger workers who "came on board", the "ones in the middle felt threatened by it." But this resistance "flipped" when they realised "it was safer to work in a robotic operation than a manned operation." As if devolving responsibility for job losses to the system's 'life of its own', Martin remarks that "we didn't spread this autonomy." He says they "thinly spread it" so autonomous mines competed with non-autonomous mines "and then you have the natural rivalry between general managers." Some said: "This stuff will never beat my manned fleets! And in the early days, they did." But then "somebody changes two lines of code in the machine system and productivity goes up." He laughs, and I imagine frustration and shame felt by managers of non-automated mines.

I ask Martin if he's concerned about losing workers' institutional memory. He laughs and says with conviction, "as you lose your tribal memory, you have system-based memory, and that's the cognitive computing platforms. When the systems are making the call, they're dealing with tens of millions of data learning points. Where is corporate memory in that world?" My feeling of deflation at Martin's certitude is briefly relieved by his political concerns. He asks, "you can run a mine from anywhere, people and operators are going to make a decision on the mine site themselves, and that is a good thing. But who controls the data and the knowledge?" Martin's ambivalence echoed my earlier conversation with Harry, the equipment manufacturer who questioned "who should get excited about that world? As an engineer you might get excited applying technology, maths and computer algorithms. Shareholders will be happy. The people left in the workforce are probably 
going to be happy because their jobs are more satisfying. But as a society, should we be happy about that? I don't know." Given their conviction, I found this ambivalence both alarming and reassuring.

\section{Complex affectivities}

After my boardroom humiliation, Martin's enthusiasm for automation induced a new set of feelings that sharpened my acknowledgement of our formative relation with our milieus. Feeling matters because bodily responses to a situation are contingent on how bodies are affected. Yet when considered ecologically, affectivity becomes more complicated as bodies are immersed in ongoing life situations that become felt in complex ways. Murphie (2018) is again instructive, describing how feelings are always 'in a complex tangle of differential relations: to each other; to happier propositional feelings concerning life; to degrees of acquiescence... and to the micropolitics of multiple real goings-on in every instance of living' $(2018,20)$, from one moment to the next. As this encounter proceeded it inducted a spectrum of feelings. I was thrilled that Martin gave me time and his enthusiasm was initially infectious. Yet as automation became justified through a combination of military metaphors and capitalist logics, the violence I perceived in the previous story became sharpened. As if the advancing storm front in the first story had finally arrived, I became troubled by Martin's devolution of responsibility to the system's inhuman 'life of its own'. This unease intensified as it became evident that automation here was white, male mastery over this inhuman life in the service of capitalism. Pitting machines against people through tropes of 'tribal knowledge' and 'taming', I was alarmed how this colonising sense of automation was being mobilised through thoroughly racialized grammars (Atanasoski and Vora, 2019).

Feeling is contingent on durational histories. Through the force of habit, bodily capacities to be affected are shaped over time by previous events leading to the present encounter. Something that might first be felt sharply can subside over time through repeated exposure (Rose, 2018). This logic is discernible in Martin's execution of automation, where some workers initially felt threatened by new automated technology and it was this feeling that required management. Yet it was my repeated exposed to stories about 'robotic takeovers' before this interview that perhaps diminished my surprise at Martin's colonising version of automation. These durational folds are complex, so that 'something', such as automation, doesn't stay the same. Something felt in a vague, inchoate way at first might gain definition through repetition. The affectivity of Martin's expression of automation was no doubt modulated by my previous interview with Harry who drew on similar forms of expression. As gatherings of forces, refrains build through repetition, so that an image, a headline, a story-regardless of its veracity-through its refraining produces a new set of existential territories, in other words new ways of thinking and feeling (Bertelsen and Murphie, 2011). Refrains proliferate diverse responses, such that people are responding differently together (Massumi, 2015). 
In sum, bodily registrations of automation are significant not just for how I am making sense of different encounters, they are also a crucial dimension of the inauguration and management of automated systems. This 'engineering' of capacities to be affected (Thrift, 2004) is discernible in the management of workers' feelings of threat that Martin describes as well as his company's attempt to create rivalry between the managers of automated and non-automated mines. Indeed, the power of the refrain indicates that engineering feeling might be as simple as retelling a Panglossian story about the merits of automation. However, while refrains help to appreciate how such feelings take hold and how expressions of automation are received, this story also demonstrates that there is always an indeterminacy in how impressions are registered, so the success of attempts to engineer feeling is never assured. Bertelsen and Murphie (2011) explain this indeterminacy through Guattari's distinction between simple 'sensory affects' $(1996,163)$ and complex 'problematic affects' $(1996$, 199). Sensory affects relate to the simple refrains associated with, for instance, seeing an image again and again. But, in the onflow of experience, there are always multiple simple refrains taking place, making the picture more complex. The relations between these simple refrains express themselves in 'problematic affects'. For me, the simple affects of encountering a headline about automation redundancies, followed by a humiliating dressing-down by a pair of mining executives, followed by an excitable story of automation, interspersed with countless other encounters, envelops me in a 'problematic affect', a complex refrain where clarity is not assured. Indeed, in spite of their conviction, Martin and Harry's ambivalence concerning both the management of knowledge in automated systems and questioning their benefit to society perhaps indicates their own envelopment in problematic affects. Taking seriously our ongoing experiential immersions in the evolution of debates on automation is to admit how complex refrains can introduce ambivalence in the responses that are produced in us. Rather than claiming to know automation, it might be necessary to admit confusion about what is going on.

\section{Story 4: Encountering benevolent evacuation}

Lisa was an occupational trauma support worker for mine sites. Her expression transports me from our beige meeting room to the dusty intensities of the desert. "It's a seriously different world," she says, "the most awful conditions." She was initially shocked at mining companies' control over employees' schedules, dress, and food, which "took away their autonomy," and she describes how she tried to enhance their living situation with a veggie garden, new sofas, and sharing favourite YouTube videos during their daily meeting. It was the first time I heard miners being described as vulnerable bodies, rather than automatons to be managed. However, partly because of increased automation, wages have dropped and there have been many redundancies. I am confronted by Lisa's 
stories of desperate situations, some involving suicide, and I feel anger at how distant managers seem from these vulnerabilities. In fighting for the jobs that remain after automation, Lisa worries that miners experiencing poor mental health are not speaking out. "Stick your head up and you will lose your job," she says. She recounts a scene involving miners alighting from buses after a day's work. "They are covered in red dirt, just look at the heavy-eyed weariness. It's like the industrial factories of the nineteenth century, subhuman, the way we are treating people."

Sometime later, my conversation with Reece, a manager for an equipment manufacturer, takes a more benevolent tone. He says the industry has to "rescue" miners from the environments that Lisa described. My memory of Lisa's anachronistic description of exhausted miners seemed to intensify the force of Reece's sentiment. He says, "we're going to move the operators out of that environment, which is great." He says, "we're gonna put them in a control room, air conditioned, they see the sun when they go for a coffee break." Reece describes a mine overseas that introduced automation. They had a technology issue which threatened to "throw all the operators back underground." He says that the operators threatened to strike, as if verifying his conviction that automation is a benevolent rather than destructive force. He's surprised that the unions push back against automation. I carry these thoughts to a later conversation with Deborah, a mining educator. She expresses scepticism about retraining miners to work in control rooms, planting doubt about Reece's sentiments. "You can easily make people redundant and recruit other people," she says. "Personally, I don't think they'll be retraining." She senses how nervous people are. "They can see it coming. Word spreads fast."

Through these three encounters I sensed the relentlessness of the jobs threatened by automation. Lisa crystallised this for me through her recollection of a conversation with a trainer who tells prospective truck drivers to "go home and choose somewhere that's five kilometres away and spend the next twelve hours going backwards and forwards and then come back and tell me if you're still interested." But even Lisa admitted there was "incredible camaraderie, people who just loved their jobs." My conversation with Brian, a director of a small mining company, accentuated Lisa's earlier description of these intimate communities. "There's not one true story," he says. "For some people, they've been driving the trucks all their lives." They're communities that don't take kindly to "seagulls" from the city HQ that come in and "just shit on you." But his tone shifts. "Trying to tell them they're going to be displaced. That's a hard one," he says, throwing his arms up. He repeats Reece's point that they are trying to reassign workers. As if attempting to dampen the situation he's just talked up, he says "anyway, I don't believe all sites are going to go autonomous because there probably isn't a good business case. And it takes a lot of time to do things."

\section{Empathetic affectivity}


After the previous story where automation was expressed through military metaphors and capitalist logics, these stories about people on the receiving end of automation seem to change what automation is through a different articulation of bodily feeling. Here, feelings are not object-targets of manipulation. Instead, feelings are being expressed in terms of a duty of care to evacuate miners from inhumane workplaces, thereby also revealing diagnoses about miners' depleted bodily capacities. Certainly, Lisa and Deborah's roles highlight the entrenched gendered divisions of labour that characterise care work in this sector. However, these stories raise crucial questions about how we make sense of our feelings and those of others. Wilsons's writing on the ethics of attunement are instructive, concerning our responsibility to the other in an encounter. She argues that 'attunement might be taken to be our openness to perceive and deal with what we encounter-an openness to the unknown' $(2017,465)$. However, she stresses that 'at the same time, non-attunement is taken to be those moments where we fail to 'pick up' how another body might be feeling. These words resonated as my fieldwork progressed. The more stories that I heard about automation, the less certain I was becoming about how to make sense of my bodily responses. This complexity was being intensified by virtue of listening to automation stories that articulated how the feelings of others were variously accommodated, suppressed, or ridden over roughshod.

Gammerl et al. (2017) suggest that it can be tempting to assume that what bodies are feeling is more or less accessible and, therefore, comprehensible. While certain 'affective states', understood as repeated and therefore enduring affects, might come to be associated with particularly joyful or sad situations, the bodily feelings that I was experiencing concerning automation were becoming difficult to make out. Hearing Lisa's story that automation was intensifying the precarity that some miners were experiencing on top of already difficult working conditions, created a sadness in me. But hearing Reece's story that extolled the benefits of removing miners from inhumane worksites made me feel more positive about automation's benevolence. However, Brian and Lisa's suggestion that many miners love their jobs induced a suspicion for me about the veracity of Reece's claim which was heightened by Deborah's cynicism about whether workers will be reassigned. These stories taken together created a confused set of feelings in me that were difficult to reconcile. Ensnared within the onflow of these complex refrains of automation, how different bodies become attuned to what becomes more complicated when considering the ongoing transductive work of simple and problematic affects that means that what is felt has a contingency and, therefore, an instability.

Fieldwork was teaching me that being receptive to the feelings of others involves real labour. These labours of receptivity are arguably underplayed in calls to increase one's powers of acting. This imperative at the heart of Foucault's later writing on ethics emphasises the importance of self- 
forming techniques that bodies undertake to work on their powers of acting. However, in encountering these divergent stories of automation, enhancing only one's power of acting comes at the expense of how we might work on our passive affections, to increase our capacities to be affected, to feel. This is an important challenge, as Murphie suggests that potentially 'catastrophic' disruption concerning automation is 'felt and thought with intensity, yet, in that it is not easily accommodated to given habits of feeling, remains unfelt and unthought' $(2018,19)$. So, how might we work on our passive affections, to better understand the evolution of automation by becoming attuned to the multiplicity of ways that others are feeling automation? As fieldwork proceeded, I was learning that one small way of working on our passive affections is through the telling and listening to stories. There is, of course, a labour to both the telling and the listening, but this is precisely how we work through feelings that are not easily accommodated in our current habits of feeling. We experiment with thoughts, voice them, and see what tendencies and dispositions they activate, what part of our multiple subjectivities they call on and strengthen.

\section{Story 5: Encountering dull games}

Back in the capital city, Theresa is walking me to a new control room that has been spectrally present in people's stories. As we walk, she shares how they're striving for workplace equality and the exhaustive recruitment procedure to achieve this. Thirty percent of people here previously worked in on a mine site, but the focus is on 'capabilities' rather than mining experience. She concedes that the pay downgrade from $\$ 180 \mathrm{k}$ on a mine site to $\$ 110 \mathrm{k}$ at the control centre might have put some off, and the shifts are still 12 hours. Theresa previously worked at mine sites and says you can monitor people with greater efficacy here. We enter a vast room with banks of monitors clustered in circles. Each of the fourteen circles is a mine site, made up of six or so screens. The two on the left are live streams of conveyor belts. It's a surreal feeling being in the middle of a city seeing the sun glinting on machinery thousands of kilometres away. Theresa says the top screens are system diagrams depicting loaders, pipes and conveyors to help ex-miners with the transition. The bottom screens are just numbers, and this is what they're moving to.

I recall an interview with Jon, an equipment manufacturer, who told me that these control rooms meant that mines were becoming "geek friendly" and that mining companies were trying to appeal to gamers. In a trial where underground mine operators and office workers were put head-to-head, the latter beat the former "because the operators still need to hear the engine rev up to get the hydraulics right. The feel is important because when you're stood on a machine and you load, you get a certain feeling from the machine which you don't get when you sit on the surface." He says he 
would much rather "put a kid that plays video games every day as an operator on an autonomous machine than a traditional operator because they don't understand what actually happens to the machine." Jon says, excitingly, it's a game "as you're getting points every time you get a load and you've got the competitiveness between the operators." However, a while later, Jon concedes "It's a boring job, as exciting as it might sound. It's boring sitting there loading, press the button, now you wait for the next load. Loading... Press the button now. You can only eat so many peanuts and drink so much coke in a shift."

Theresa leads me to a workstation operated by six people. Some are some chatting, a few are slumped in their chairs. Theresa introduces me to Nathan who is in his early twenties. He worked at a mine site after he left school. Before he came here, he worked in a washer section which was looked down on by other miners. It was awful work and there was nothing for him or his partner to do there. He describes the processes he's watching on the screens, checking and monitoring levels. You need the video feeds as the sensors gum up and you get false readings. A ribbon blowing in the breeze indicates the picture is live. He speaks into his headset. There is quite a bit of communication between the control room and the on-site operators. It sounds procedural but apparently there is repartee too. Training involves being on the mine site to make friends with co-workers and to become exposed to what you're operating. The guy next to Nathan says he found it hard adjusting to city life and often forgets that the city is on his doorstep.

We move to another mine and Theresa introduces me to another man but then gets called away. Wolf is in his late thirties and has a long history of working on mine sites. He says that he misses working on site, the camaraderie with the lads and the skills he had developed. I remember Jon, the equipment manufacturer, telling me that "nothing can replace mine engineering experience." The example he gave stuck with me, of a production manager on a mine in the States who would say "Shhh, just be quiet...alright... that section of the mine is moving. They can feel stuff that me and you don't pick up on." He says no sensor can replace that experience. Back at this workstation, Wolf says they used to be able to get up to things out of the eye of the bosses. Again, my mind goes back to a previous interview with Larry, a mining engineer, who reminisced about a time when he drove a truck. "It was great fun," he said. "You'd whack it in neutral and hit the bottom of the ramp doing sixty! I'd swing my wheel around, the whole truck would skid out and there'd be dirt flying everywhere! You need something. It's suicidally boring," he said. As Theresa heads back to the workstation, Wolf says that he loves his job though, and "there is an excitement to achieving your targets." He's training a younger woman who is checking tolerance levels on a screen full of numbers.

\section{New feelings}


Through this final set of encounters, I began to appreciate Murphie's contention that 'we do not really know, in absolute or finished terms, what feeling itself is doing' $(2018,38)$. During the tour, I could sense how the new spatialities of automation manifested in the control room might be reshaping feeling. The stories told by some seemed to attest to a palpable sense of relief of being away from menial mine site roles which strongly resonated with Lisa's earlier story of the depleting conditions that many on-site workers face. However, other stories seemed to emphasise how the intensified surveillance of the control room induced a melancholia for previous ways of working, and how the labyrinthine spatiality of the mine site created opportunities for camaraderie and playfulness. Jon's story about how miners on site have developed empathy with the machines that they are handling suggested that 'feeling differently' is not a residual bodily effect of changing work conditions. Rather, it is becoming an operational imperative for increased productivity. In this sense, storytelling was a demonstration of how these multiple transitions in feeling were being comprehended and worked through.

Autonomous Marxist writers have described the rise of affective labour where value is increasingly produced from performative, cognitive activities that are intended to produce particular feelings (Lazzarato, 1996). On one hand, the mining sector is distant from the kinds of creative labours that are the concern of such writers. Yet, on the other hand, changes in technological automation such as the development of remotely-monitored automated mines, are inducing new forms of expressive work involving working with and through feelings. Through the stories I was being told, I sensed how this new workplace was creating new collectives of affecting and being affected. This was especially discernible through stories about the affinities that now have to be developed between people working in the control centre and people on the mine site. That training involves traveling to the mine site to develop friendships indicates how transitioning feelings involving trust with distant workers are now being engineered into these new automated ways of working. On reflection, the very experience of being invited to tour this facility was itself an instance of working to provoke new feeling for me, through the narration of a specific story about automation and its role in achieving workplace equality.

Following my previous encounters, I arrived at this building with an uneasy foreboding about what might happen. Yet, in spite of my initial excitement at being given a tour of the new remotecontrolled facility, the stories that I was told left me feeling ambivalent about how this form of technological automation was redefining those bodies involved. Through the juxtaposition of different stories side by side, my presentation of these encounters here is an attempt to remain faithful to their singularity, while acknowledging that such presentation has the potential to create new kinds of feeling about automation. For instance, putting Jon's narration of the gamified logics in 
control rooms that slide from excitement to boredom side by side with my encounters with control room operatives Nathan and Wolf are an attempt to incite questions about the inevitability of these feelings, highlighting the wiggle-room that exists even in the most constrained situations (Massumi, 2015). Concluding this story with Wolf's declaration of joy in exceeding targets is not to doubt the authenticity of his feeling or to pass judgement on intensified performance management. Rather, in this instance, it is to emphasise how the telling of stories has a powerful performative role that shapes dispositions and, ultimately, belief. Through this brief story, we might glimpse something of the labour that is involved working through complex feelings involving mourning the loss of a previously valued workplace and needing to become more attached to a new situation. This, I suggest, is the untold labour of contemporary technological automation: the working through in feeling of what, exactly, is taking place.

\section{Conclusion}

A quarter century ago, Rifkin declared that, 'In the years ahead, more sophisticated software technologies are going to bring civilization ever closer to a near-workerless world' (1996, xv). Though such declarations have gathered pace recently, social science responses have subjected such claims to critical scrutiny, diffusing technological determinism with an evaluation of the political forces guiding these developments through examinations of 'actually existing' automation. Certainly, these stories indicate how mining automation is taking place through specific digital equipment at remote mine sites operated from control centres located in cities, with implications for the labour that is required. However, zooming in too quickly to diagnose the political forces that might be guiding automation risks neglecting the vital epistemological process whereby different bodies come to make sense of automation. Indeed, just focusing on the site in the final story would neglect how a range of other sites and materials are centrally implicated in the production of automation, from the media reports in the first story, to the support workers in the penultimate story. Following feminist digital geographers who have championed the potentials of non-hegemonic epistemologies to disrupt dominant understanding of digital technologies, this paper has developed storytelling as a methodological technique that can draw out diverse site-specific ways that automation is expressed and made sense of.

Taking epistemology seriously acknowledges how storying automation contributes to its production. Rather than evaluating whether automation is deskilling or reskilling workers, storying provides a more complex appreciation of the multiplicity of embodiments involved, and this multiplicity produces a more distributed and changeable appreciation of power. Automation is being produced 
by stories told by differently situated bodies: by report writers, automation managers, corporate executives, equipment manufacturers, educators, occupational support workers, miners and more. The power of their stories involves the expressive forces of unsettling headlines, shaming gestures, awestruck visions, empathetic care, and accommodating habits. Yet these expressive forces work to redefine the human in relation to automation in different ways: as variously absent, suspicious, inefficient, vulnerable, and impressionable. Automation is therefore not a single technological object that is being interpreted from different angles, but rather different stories produce automation differently. If, as Rose suggests, stories are 'the events that give us a voice' $(2016,144)$, then rather than imagining automation stories as pale representations of a technical process that is taking place in some other space, storytelling is the creative rendering of spaces of automation. Storying automation is a composition of 'reals', to use Stewart's term, where 'a real is a tangle of elements somehow thrown together yet still moving in directions, singly and in clumps, and opening onto other things' $(2015,15)$. As such, automation is a socio-technical process that is encountered through the stories that we listen to and tell, and the diverse stories in this paper enhance our appreciation of the automation's multiple spatialities.

The political significance of automation stories is contingent on bodily capacities to be affected. Certainly, mining companies appreciate the significance of feeling evidenced through the creation of competition between managers, and gamification between operators that enrols bodies into new socio-spatial arrangements of labour. Yet an over-emphasis on strategic dimensions overlook the range of divergent, mixed feelings that braid these stories of automation. As Murphie (2018) suggests, we often overlook how technological disruptions come together in feeling in a vast number of ways. The resigned cynicism of an educator; momentary uncertainty voiced by an executive, shifting enthusiasm and melancholia of a control centre worker indicates how bodily affectivity is much more fluctuating. I have argued that this instability is partly a result of serial encounters, where all bodies are caught up in multiple complex refrains with different people in different places. My capacities to be affected in the control centre were modulated by prior encounters with alarmist headlines, boardroom aggressions, futurist euphoria, and benevolent care. The serial presentation of stories aimed to intensify their differences and draw out such instabilities, where each story primes the encounter with the next. Since feeling is a site of political change, rather than excising this multiplicity from our accounts, we need to intensify it, because it demonstrates the potential for a situation to be different. Telling and listening to stories is one way that we work through this multiplicity to produce something different. Far from a residual response to a real thing taking place, feeling is a transitional process and it is future creating through the way that it is redefining bodies. 


\section{Acknowledgements}

I am grateful to three anonymous reviewers who provided perceptive and generous suggestions, to Natalie Oswin for supportive editorial guidance, and to Taru Narula for assistance. Feedback from presentations of the paper at the RGS-IBG annual conference in 2018 and a seminar at Monash University in 2019 helped to clarify the argument. I am grateful to Mitch Rose and Tim Edensor for kindly reviewing a previous draft.

\section{References}

Amoore, L. and Raley, R. (2017) Securing with algorithms. Security Dialogue, 48(1), 3-10.

Anderson, B. (2019) Cultural geography II: The force of representations. Progress in Human Geography, 43(6), 1120-1132.

Anderson, B. and Harrison, P. (eds.) (2012) Taking-Place: non-representational theories and geography. Aldershot: Ashgate.

Atanasoski, N., \& Vora, K. (2019). Surrogate Humanity: Race, Robots, and the Politics of Technological Futures. Durham, NC: Duke University Press.

Bertelsen, L. and Murphie, A. (2010) Félix Guattari on Affect and the Refrain. In M. Gregg and G. Seigworth (eds.) The Affect Theory Reader. Durham: Duke UP. 138-156.

Birtchnell, T. and Elliott, A. (2018) Automating the black art. Geoforum, 96, 77-86.

Bondi, L. (2014) Understanding feelings. Emotion, Space and Society, 10, 44-54.

Boyer, K. and England, K. (2008) Gender, work and technology in the information workplace. Social \& Cultural Geography, 9(3), 241-256.

Brigstocke, J. and Noorani, T. (2016) Posthuman attunements: Aesthetics, authority and the arts of creative listening. GeoHumanities, 2(1), 1-7.

Brynjolfsson, E. and McAfee, A. (2014) The Second Machine Age. London: WW Norton \& Company.

Elliott, A. (2019) The Culture of Al. London: Routledge.

Elwood, S. and Leszczynski, A. (2018) Feminist digital geographies. Gender, Place \& Culture, 25(5), 629-644.

Fields, D. (2019) Automated landlord: Digital technologies and post-crisis financial accumulation. Environment and Planning A: Economy and Space, forthcoming.

Ford, M. (2015) The Rise of the Robots. New York: Basic Books.

Forlano, L. and Halpern, M. (2015) Reimagining work: entanglements and frictions around future of work narratives. Fibreculture, 26, 32-59.

Frey, C. and Osborne, M. (2015) Technology at Work: The future of innovation and employment. Citi GPS. 
Gammerl, B., Hutta, J. and Scheer, M. (2017) Feeling Differently: approaches and their politics. Emotion, Space and Society, 25, 87-94.

Hayles, N. K. (2006) Unfinished work: From cyborg to cognisphere. Theory, Culture \& Society, 23(78), 159-166.

Hayles, N. K. (2014) Cognition everywhere. New Literary History, 45(2), 199-220.

Hopkins, D. and Schwanen, T. (2018) Automated mobility transitions: governing processes in the UK. Sustainability, 10(4), 956.

Irani, L. (2015) Difference and dependence among digital workers. South Atlantic Quarterly, 114(1), 225-234.

Kanngieser, A. (2013) Tracking and tracing: Geographies of logistical governance and labouring bodies. Environment and Planning D: Society and Space, 31(4), 594-610.

Kinsley, S. (2019) 'Subject/ivities', in Ash et al. (eds.) Digital Geographies. London: Sage. 153-163. Lazzarato, M. (1996). Immaterial labor. Radical thought in Italy: A potential politics, 1996, 133-47. Lorimer, H. and Parr, H. (2014) Excursions - telling stories and journeys, Cultural Geographies, 21(4), 543-547.

Massey, D. (1984) Spatial Divisions of Labour. Basingstoke: Macmillan.

Massumi, B. (2015) Politics of affect. Cambridge: Polity.

Murphie, A. (2018) On being affected: feeling in the folding of multiple catastrophes. Cultural Studies, 32(1), 18-42.

Richardson, L. (2018) Feminist geographies of digital work. Progress in Human Geography, 42(2), 244-263.

Richardson, L. (2019) Platforms, markets, and contingent calculation. Antipode, online early. Rifkin, J. (1996) The End of Work. New York: Tarcher.

Rose, G. (2017) Posthuman agency in the digitally mediated city: exteriorization, individuation, reinvention. Annals of the American Association of Geographers, 107(4), 779-793.

Rose, M. (2016). A place for other stories: Authorship and evidence in experimental times. GeoHumanities, 2(1), 132-148.

Pink, S. and Sumartojo, S. (2018) The lit world: Living with everyday urban automation. Social \& Cultural Geography, 19(7), 833-852.

Savat, D. and Chau, C. (2017) Anxious robots, desiring repression, generating profit. Transformations, 29, 52-68.

Shepard, M. (2013) Minor urbanism: everyday entanglements of technology and urban life. Continuum, 27(4), 483-494.

Sheppard, E. (2013) Thinking through the Pilbara. Australian Geographer, 44(3), 265-282. 
Stephens, E. and Heffernan, T. (2016) We Have Always Been Robots. In Robots and Art (pp. 29-45). Springer, Singapore.

Stewart, K. (2015) 'New England Red,' in P. Vannini (ed.) Non-Representational Methodologies. 1933.

Stewart, K. (2016) The point of precision. Representations, 135(1), 31-44.

Stiegler, B. (2010) For a new critique of political economy. Cambridge: Polity.

Thrift, N. \& French, S. (2002) The automatic production of space. Transactions of the Institute of British Geographers, 27(3), 309-335.

Thrift, N. (2011) Lifeworld Inc. Environment and Planning D: Society and Space, 29(1), 5-26.

Wajcman, J. (2017) Automation: is it really different this time? The British Journal of Sociology, 68(1), 119-127.

Wallace, I. (1985) Towards a geography of agribusiness. Progress in Geography, 9(4), 491-514.

Wilson, H. (2017) On geography and encounter. Progress in Human Geography, 41(4), 451-471.

Wise, J. M. (1998) Intelligent agency. Cultural Studies, 12(3), 410-428.

Woolley, S. and Howard, P. (2016) Automation, algorithms, and politics. International Journal of Communication, 10(9), 4882-4890. 


\section{University Library}

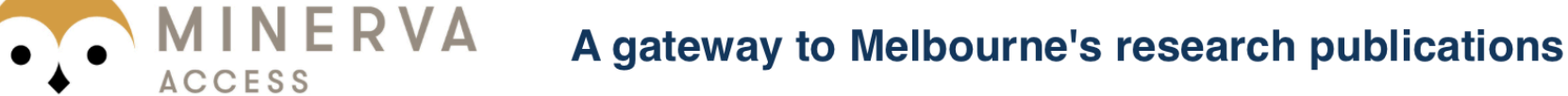

Minerva Access is the Institutional Repository of The University of Melbourne

Author/s:

Bissell, D

Title:

Encountering automation: Redefining bodies through stories of technological change

Date:

2020

Citation:

Bissell, D. (2020). Encountering automation: Redefining bodies through stories of technological change. Environment and Planning D: Society and Space, 39 (2), https:// doi.org/10.1177/0263775820963128.

Persistent Link:

http://hdl.handle.net/11343/247892 